\title{
Organ donation after cardiac death: legal and ethical justifications for antemortem interventions
}

\author{
Bernadette Richards and Wendy A Rogers
}

工 $\mathrm{n}$ n comparison with other wealthy nations, Australia has a relatively low rate of deceased donor organ donation (10 donors per million population in 2005). Whatever the reasons for this, ${ }^{1}$ there are many people who could benefit from organ donation for whom organs are unavailable. ${ }^{2}$ In 2005, there were 204 organ donors, leading to 736 solid-organ transplants, against an organ transplant waiting list of 1716 people. ${ }^{3}$ Among the 204 organ donors were nine people whose organs were donated after a diagnosis of death by cardiac criteria. Donation after cardiac death offers an alternative pathway to donation for people who do not meet the criteria for donation after brain death. ${ }^{4}$ Donation after cardiac death, although not a new procedure, was relatively neglected once there was widespread acceptance of organ donation after brain death. Given the relative scarcity of donated organs, there has been renewed interest in donation after cardiac death, both in Australia and internationally. ${ }^{5}$ International data indicate that it increases the number of donor kidneys. ${ }^{6}$ In Australia to date, predominantly kidneys have been procured from donors after cardiac death, but other organs including lungs and the liver will increasingly be procured in the future. In most instances, donations after cardiac death have occurred subsequent to requests from donor patients' families.

Donation after cardiac death raises a number of specific ethical and legal issues, including potential or perceived conflicts of interest, treatment withdrawal processes, uncertainty about time of death, and consent. In this article, we focus exclusively on the legal and ethical permissibility of performing interventions before death to improve the likely success of organ transplants. Organs procured after cardiac death are at increased risk of damage secondary to warm ischaemia and to thrombotic insults, and have a higher incidence of delayed graft function than organs procured after brain death. ${ }^{7}$ Current best practice includes antemortem administration of drugs to minimise the risk of organ damage in the period just before and after the death of the potential donor. ${ }^{7}$ It is also advisable for treatment withdrawal and terminal palliative care to take place in or adjacent to the operating theatre so that surgery can proceed as soon as practicable after death has been declared and a stand-down time observed. Some protocols for donation after cardiac death include antemortem cannulation of the femoral vessels to facilitate rapid infusion of organ-preserving solutions after death. A question that is currently unresolved in Australia is whether or not antemortem interventions, such as administration of drugs or femoral cut-down, are ethically and legally permissible. Anecdotal evidence indicates that, at present, antemortem interventions are not performed in Australia due to concerns about the legality of consent (Dr Deborah Verran, Chair, Organ Donation Network of New South Wales/ Australian Capital Territory, Donation after Cardiac Death Working Party, personal communication, 3 February 2007).

\section{Ethical issues}

Consent is a critical mechanism for demonstrating respect for people and their wishes. The current Australian opt-in system for organ donation allows people to register their written consent to donation
ABSTRACT

- Organ donation after cardiac death increases organ availability, but raises several legal and ethical issues, including consent.

- Medical interventions for people who are unconscious usually require guardian consent and must meet patients' best-interests standards.

- Antemortem procedures can improve the success of organ transplant after cardiac death, but do not serve the patient's medical interests, and it is contentious whether consent for antemortem interventions is legal under current Australian guardianship legislation.

- We argue that consent decisions should take patients' wishes as well as their medical interests into account.

- Antemortem interventions are ethically and legally justified if the interventions are not harmful and the person concerned wished to be an organ donor.

MJA 2007; 187: 168-170

with the Australian Organ Donor Register (AODR). ${ }^{8}$ In the absence of formal registration, family members can communicate a person's desire to donate and provide the necessary legal permissions. The current AODR form for potential donors does not distinguish between donation after cardiac death and donation after brain death, making it possible to argue that the consent given by registrants may only be assumed for organ donations in situations familiar to the public, namely donation after brain death. For consent to be ethically valid, it must be informed and given without coercion. Without explicit information on antemortem interventions, it is not clear that a person signing the register is consenting to nontherapeutic interventions or removal to an operating theatre before death.

These objections lose force, however, when we consider consent in more routine circumstances. Consent for an appendicectomy, for example, does not usually include consideration of the individual component procedures, such as the surgeon's incision, removal of appendix, type and technique of sutures, antibiotics, etc. Implicit in the consent to the broad procedure is a consent to all reasonable steps to facilitate successful removal of the appendix. Similarly, a consent to organ donation could be viewed as a consent to take all reasonable steps to ensure that the operation is successful, resulting in transplantation of viable organs. On this view, consent registered with the AODR, or a known wish to donate, would be ethically sufficient to allow donation after cardiac death, including any necessary antemortem interventions.

A second ethical consideration is that of avoiding harm. Do antemortem interventions harm the patient? These interventions include removal to an operating theatre, administration of heparin, steroids, antibiotics or other drugs, or cannulation of femoral vessels. Moving the patient to theatre before death may disturb the patient or the family or both, and jeopardise the patient's medical 


\begin{tabular}{|c|c|c|c|}
\hline \multicolumn{4}{|c|}{ Summary of the provisions for the wishes of the patient in Australian Guardianship Acts } \\
\hline State & Legislation & Section & Summary of provisions \\
\hline $\mathrm{ACT}$ & $\begin{array}{l}\text { Guardianship and } \\
\text { Management of Property } \\
\text { Act } 1991\end{array}$ & s4(2)(a) & $\begin{array}{l}\text { "... the protected person's wishes, as far as they can be worked out, must be given effect to, } \\
\text { unless making the decision in accordance with the wishes is likely to significantly adversely affect } \\
\text { the protected person's interests." }\end{array}$ \\
\hline NSW & Guardianship Act 1987 & s4 and s32 & $\begin{array}{l}\text { General guardianship principles emphasise that the welfare and interests of such persons should } \\
\text { be given paramount consideration, and that the views of such persons should be taken into } \\
\text { consideration. }\end{array}$ \\
\hline NT & $\begin{array}{l}\text { Adult Guardianship } \\
\text { Act } 2006\end{array}$ & s4 & $\begin{array}{l}\text { Considerations relating to best interests include a direction that the wishes of a represented } \\
\text { person are, wherever possible, given effect to. }\end{array}$ \\
\hline \multirow[t]{2}{*}{ Qld } & \multirow{2}{*}{$\begin{array}{l}\text { Guardianship and } \\
\text { Administration Act } 2000\end{array}$} & s61 & (ii) health care that is, in all the circumstances, in the adult's best interests \\
\hline & & Schedule 1 & $\begin{array}{l}7(4) \text { "... the principle of substituted judgment must be used so that ... [any decision maker] ... } \\
\text { considers [what] would be the adult's views and wishes." }\end{array}$ \\
\hline SA & $\begin{array}{l}\text { Guardianship and } \\
\text { Administration Act } 1993\end{array}$ & s5 & $\begin{array}{l}\text { Emphasis is on the individual's interests: "consideration (and this will be the paramount } \\
\text { consideration) must be given to what would, in the opinion of the decision maker, be the wishes of } \\
\text { the person in the matter". }\end{array}$ \\
\hline Tas & $\begin{array}{l}\text { Guardianship and } \\
\text { Administration Act } 1995\end{array}$ & s6(c) & $\begin{array}{l}\text { "The wishes of a person with a disability or in respect of whom an application is made under this } \\
\text { Act are, if possible, carried into effect." }\end{array}$ \\
\hline Vic & $\begin{array}{l}\text { Guardianship and } \\
\text { Administration Act } 1986\end{array}$ & s38 & $\begin{array}{l}\text { In determining whether treatment is in the best interests of the patient, the wishes of the patient is } \\
\text { one of the considerations. }\end{array}$ \\
\hline WA & $\begin{array}{l}\text { Guardianship and } \\
\text { Administration Act } 1990\end{array}$ & s4 & $\begin{array}{l}\text { Notes that a primary concern will be the best interests; however, decision makers must also } \\
\text { "ascertain the views and wishes of the person concerned..." }\end{array}$ \\
\hline
\end{tabular}

care. Moving the patient will inevitably cause some disruption, but it is not clear that an operating room is a worse place to die than an intensive care unit, which is where most patients with the potential to be donors after cardiac death would otherwise be cared for. There is no evidence that, in the absence of active bleeding, administration of heparin would cause sufficient bleeding to contribute to death. ${ }^{7}$ As actively bleeding patients are not usually considered for donation after cardiac death, heparin-related harms are unlikely. Heparin could be administered through established intravenous lines, and its administration would not interfere with the family's attendance at the bedside. Administration of steroids and antibiotics is unlikely to be harmful. On the other hand, cannulation of the femoral vessels is a physically invasive process that may disrupt the family, as they would need to move away while this was performed and, if the patient did not proceed to donation, the cannulas would then need to be removed.

\section{Legal issues}

In relation to the legal question of antemortem interventions to facilitate donation after cardiac death, it is well established that treatment without consent is assault. ${ }^{9}$ As patients who are potential donors after cardiac death are incapable of providing legally valid consent at the time, an alternative legal decisionmaker must be identified if there is no pre-existing consent. In non-urgent situations, there are a number of ways for this to be achieved. Patients may create anticipatory or advance directives, or appoint various kinds of legally valid guardians (eg, in South Australia, a medical agent or an enduring guardian). There are two standards used in proxy decision making: known wishes (also known as substituted judgment) or best interests. With the known-wishes standard, decisionmakers must make decisions in accordance with the known wishes of the patient; that is, what the patient would have decided for him- or herself. The best-interests standard requires proxy decisionmakers to exercise authority in the best interests of the patient. In reality, these considerations act in tandem, with decisions about what the patient would have wanted being tempered by consideration of the best interests of the patient.

In practical terms, many patients with the potential to be donors after cardiac death are unlikely to have appointed a proxy decisionmaker, so that decisions about their care fall under the Guardianship Acts. These Acts authorise an appropriately appointed guardian to make medical decisions; in situations where donation after cardiac death is possible, this is usually a relative. The Guardianship Acts vary from state to state, but there is a governing principle found in most of the Acts; for example, s5 of the Guardianship and Administration Act 1993 (SA) refers both to the best interests of the patient and his or her wishes, if known. Similar provisions are present in each state: Guardianship and Management of Property Act 1991 (ACT), s5A; Guardianship Act 1987 (NSW), s4, s32 and s46; Adult Guardianship Act 2006 (NT), s4 and s21; Guardianship and Administration Act 2000 (Qld), s61 and Schedule 1 s7(4) and s7(5), along with s12 which sets out the health care principle; Guardianship and Administration Act 1995 (Tas), s6 and s43; Guardianship and Administration Act 1986 (Vic), s38; Guardianship and Administration Act 1990 (WA), s4 and s51.

The question of patients' wishes is relatively straightforward if patients have registered their consent on the AODR, or their families are aware of their wishes through discussions before the critical incident. We have argued above that it may be ethically valid to consider that consent to organ donation includes consent to all measures necessary to ensure that organ donation is successful, especially where these are not harmful to the patient. If we accept this, there should be no barrier to guardian consent for antemortem interventions, on the grounds that this is consent in line with the person's known wishes.

Can antemortem interventions be justified legally under the bestinterests standard? This is a more complicated question. Antemortem interventions are not necessary to further the physical wellbeing of the patient. Rather, these interventions to preserve organ quality 
are in the interests of the potential organ recipient. As they are not in the interests of the patient, it could be argued that the guardian cannot give consent because the intervention is beyond his or her authority. Indeed, this position is reflected in the recently released Organ donation after cardiac death: NSW guidelines. ${ }^{10}$ We believe that this view relies on a limited interpretation of best interests, and is not within the spirit of Australian guardianship legislation. In the legislation of each state, the basic principles are clearly set out. The focus is on the best-interests principle, but each of the Guardianship Acts also includes reference to the wishes of the patient (see Box). This means that, even in the absence of registration on the AODR, the family may be able to give consent to antemortem interventions if there is clear evidence that the patient wished to be an organ donor. This can be justified on the grounds that a procedure which is not harmful to the patient, and which has the potential to further the patient's wishes, can be viewed as being in his or her best interests.

The issue of best interests was addressed by the UK House of Lords in their decision on Airedale NHS Trust $v$ Bland, ${ }^{11}$ and the interpretation of best interests was recently cited with approval by the Administrative Decisions Tribunal of NSW. ${ }^{12}$ The House of Lords decision concerned withdrawing life-sustaining treatment from 17-year-old Anthony Bland who had post-coma unresponsiveness (known as persistent vegetative state) after being crushed in the Hillsborough soccer riots in 1989. His interests were said to include his views and personality as well as how his family perceived and remembered him. ${ }^{11}$ In particular, the Law Lords ${ }^{11}$ acknowledged that a range of considerations should be taken into account when determining best interests: "The principle of the best interests of an incompetent ... encompasses wider considerations [than futility of treatment]". A person is more than a biological collection of organs; they have thoughts and opinions, a personality and an interest grounded in these intangible considerations. When that person is dying, his or her physical interests diminish. The only interests left to be furthered are intangible interests, such as a wish to donate organs. In Australia, the High Court has emphasised that the "best interests approach offers no hierarchy of values" to guide decisionmaking processes in difficult areas, and neither does it provide a general legal principle. ${ }^{13}$ If we agree that it is in a person's interests to have his or her wishes fulfilled, then taking all necessary measures to do so seems a logical step, especially when this may be done under the authority of the Guardianship Acts.

\section{Conclusion}

The supply of organs available for transplantation in Australia may be increased by donations after cardiac death, with success enhanced by antemortem interventions. We argue that it is ethically justified to perform non-harmful antemortem interventions on patients whose wishes to donate organs after death are known, either through AODR registration or from their relatives. Facilitating organ donation in these circumstances respects the wishes of the dying, meets ethical requirements for consent, and does not harm the patient. It is legally valid for relatives to give consent for antemortem interventions under guardianship legislation when the patient's wishes are known, as respecting his or her wishes is an important part of acting in the patient's best interests. We acknowledge that this is not a universally accepted interpretation of guardianship legislation (for example, see the NSW guidelines ${ }^{10}$ ). To facilitate practice in this area, we need a more certain legislative framework. This could be achieved by specifically addressing consent for antemortem interventions in the Human Tissue Acts, which govern other aspects of organ donation. Using the Human Tissue Acts would avoid state-by-state interpretations of the Guardianship Acts, which are not primarily concerned with organ donation. Legislative change, together with informed community debate about donation after cardiac death, will ensure that that those who wish to donate organs after death understand the implications of their decisions, and families and practitioners are legally protected when they act to fulfil the wishes of potential donors.

\section{Acknowledgements}

We thank members of the Health Ethics Research Theme of the Ethics Centre of South Australia and Dr Deborah Verran for helpful discussions on the ideas presented here.

\section{Competing interests}

Wendy Rogers was Deputy Chair of the Australian Health Ethics Committee's Organ Donation Working Party.

The views in this article are ours alone and do not represent the official views of this working party or any other organisation. Neither of us has any financial or other connection with any aspects of organ donation, or any direct interest in organ donation for personal reasons.

\section{Author details}

Bernadette Richards, BA, DipEd, LLB(Hons), Lecturer ${ }^{1}$ Wendy A Rogers, BMBS, FRACGP, PhD, Associate Professor ${ }^{2}$

1 Law School, University of Adelaide, Adelaide, SA.

2 Medical Ethics and Health Law, Department of Medical Education,

Flinders University, Adelaide, SA.

Correspondence: wendy.rogers@flinders.edu.au

\section{References}

1 Opdam $\mathrm{H}$, Silvester W. Identifying the potential organ donor: an audit of hospital deaths. Intensive Care Med 2004; 30: 1390-1397.

2 Matthew T, Faull R, Snelling P. The shortage of kidneys for transplantation in Australia [editorial]. Med J Aust 2005; 182: 204-205.

3 The Australia and New Zealand Organ Donation Registry. Annual report of the Australia and New Zealand Organ Donation Registry, 2006. http:// www.anzdata.org.au/ANZOD/ANZODReport/anzodreport.htm (accessed Feb 2007).

4 Bhonagiri D, Wills P. Potential for organ donation in Victoria: an audit of hospital deaths [letter]. Med J Aust 2007; 186: 157.

5 Australians donate. Proceedings of the Non-Heart-Beating Donation Symposium; 2004 Nov 26; Melbourne.

6 Jacobs RW, Kievit JK, Nederstigt AP, et al. Non-heartbeating donors: are they worth the effort? Curr Opin Nephrol Hypertens 1998; 7: 655-658.

7 Bernat JL, D'Alessandro AM, Port FK, et al. Report of a National Conference on Donation after cardiac death. Am J Transplant 2006; 6: 281-291.

8 Medicare Australia. Australian Organ Donor Register. http://www.medicareaustralia.gov.au/yourhealth/our_services/aaodr.shtml (accessed Feb 2007).

9 Rogers v Whitaker (1992) 175 CLR 479.

10 New South Wales Health. Organ donation after cardiac death: NSW guidelines. Sydney: NSW Health, 2007: 6. http://www.health.nsw.gov.au/ policies/gl/2007/GL2007_012.html (accessed Jun 2007).

11 Airedale NHS Trust v Bland [1993] AC 789.

12 WK v Public Guardian (No 2) [2006] NSWADT 121.

13 Secretary, Department of Health and Community Services v JWB and SMB (1992) 175 CLR 218 (Marion's case), per Brennan J, 270.

(Received 8 Feb 2007, accepted 17 May 2007) 